\title{
A MEMÓRIA NA MISTAGOGIA JOÃOCRUCIANA
}

\author{
Marcelo Martins BARREIRA ${ }^{1}$
}

- RESUMO: A importância da memória na Subida do Monte Carmelo advém de sua capacidade de manter as experiências agradáveis ou desagradáveis, permitindolhes que se aprofundem e se ramifiquem na alma, com graves repercussões na vida espiritual. A memória busca, no arquivo de imagens e vivências, dados que alimentem a agressividade, a cobiça, a paixão, soberba e vingança; com o agravante de que não tem limites de duração, o que lhe permite realizar continuamente esta sua ação. A alma, quando retém e apreende preferencialmente a lembrança de amarguras passadas, acaba não se abrindo para a ação divina que ora se lhe manifesta. Por isso, para que participe diretamente da comunhão divina, da mesma forma que as demais potências espirituais, a memória deve esvaziarse. A purificação e o esvaziamento da memória não prescrevem o esquecimento do que se conhece ou se lembra, apenas manifestam a necessidade de ela ficar livre de considerações particulares numa esperança que a purifica a fim de deixá-la livre para receber a comunicação divina.

- PALAVRAS-CHAVE: alma; memória; união de amor; João da Cruz; Deus.

João da Cruz herdou da tradição agostiniana ${ }^{2}$ e da escola carmelitana a divisão tripartite da alma - colocando a memória como potência espiritual

1 Professor Adjunto do Departamento de Filosofia da Universidade Federal do Espírito Santo (UFES). Artigo recebido em mar/07 e aprovado em jun/07.

2 Apenas no parágrafo 15 da primeira estrofe da Chama Viva de Amor, versão B, João da Cruz parece ecoar Agostinho [Memoria, intelligentia, voluntas (...), haec tria (...) una vita, una mens, una substantia. In: Sobre a Trindade X, 11, 18; ver o livro XIV - cabe notar: João da Cruz emprega faculdades em duas vezes, e tão-somente como capacidade natural; potências, ao contrário, 390 vezes; ver Astigarra, Borrell \& Martín de Lucas, 1990, s/pág., edição eletrônica] associando cada pessoa da Trindade a uma diferente potência espiritual: o Pai à memória; o Filho ao entendimento; e, o Espírito Santo à vontade (ver Bord, 1971, p.94 e p.291-300; VV.AA. Dictionnaire 1932, t.I, col.437; Gardeil, 1927, v.I, p.96-97 e Josaphat, 1995, p.100). 
e distanciando-se de Tomás (Tomás de Aquino, 1947, I, 79, p.7). Assim procedeu por considerar essa divisão mais fácil a seus propósitos: explanar acerca do aperfeiçoamento espiritual da alma pelas três virtudes teologais e, como mistagogo, fazê-la unir-se misticamente com Deus.

Estabelecendo um contraponto com a tradição tomásica, enfocaremos neste artigo o segundo e terceiro livro da célebre e importante obra Subida do Monte Carmelo. Obra que nosso autor dedicará à memória e à esperança, que a purifica, a metade dos capítulos dedicados à fé e ao amor, as outras duas virtudes teologais (3S 1-15; Ruiz Salvador, 1995, p.207-20). Apesar do menor número de páginas, a importância da memória advém de sua capacidade de manter as experiências agradáveis ou desagradáveis, permitindo-lhes que se aprofundem e se ramifiquem na alma, com graves repercussões na vida espiritual.

Além da preocupação em eliminar os contrastes entre Tomás de Aquino e João da Cruz, Maritain preocupa-se em dar sustentação epistemológica à teologia espiritual, fornecendo-lhe um campo específico e um padrão que justificariam sua existência enquanto ciência autônoma. Contudo, Maritain atribui aos escritos joãocrucianos um valor exclusivamente pedagógiCo, privando-os do caráter ontológico. ${ }^{3}$ Assim, apesar de as potências espirituais da alma serem divididas por João da Cruz conforme a tradição agostiniana, Maritain não vê isto como um problema (Maritain, 1931, p.6558); pois, as lembranças "às vezes têm para o sujeito valor prático, elas compõem a trama desse passado sempre crescente que, como diz Bergson, faz constantemente pressão sobre o presente para ocupar-se (com as coisas); será a memória" (idem, p.656).

Daí que Maritain, ante sua perspectiva prática, justifica o rompimento de nosso autor com toda a tradição das escolas (Maritain, 1931, p.657), haja vista que esta divisão propicia a correspondência das três potências espirituais da alma com as três virtudes teologais. Concepção indefensável, segundo este, sob um ponto-de-vista ontológico, ${ }^{4}$ no entanto, colocando-se do ponto de vista da ciência praticamente prática dos atos humanos, que faz de seus (João da Cruz) ensinamentos sobre a memória uma parte tão importante (e tão poderosamente original) de sua obra; mostra-se, junto com santo Agostinho, como um daqueles que penetraram mais profundamente na psicologia da memória (idem, p.657-8, grifo no original). Logo, apesar da diferença entre a mistagogia de Tomás e a de João da Cruz - a postura espe-

3 Para Ruiz Salvador, contudo, não há fundamento para estabelecer esta clara distinção entre guia espiritual e doutor, entre caráter teológico e finalidade pedagógica (Ruiz Salvador, 1968, p.289-90).

4 Diferentemente, Morel afirma o valor ontológico do sistema joãocruciano (ver Morel, 1960/61, v.II, p.30). 
culativa daquele (filosófica e teológica) e a prática deste (ascético-mística) -, haveria entre ambos um acordo de fundo. Conquanto Maritain tenha minimizado tal diferença, acompanharemos o estudo de André Bord em sua demonstração de que o arcabouço teórico de nosso autor discorda de Tomás no que toca à memória. ${ }^{5}$

Para Tomás, a memória intelectual não é uma potência distinta do intelecto passivo. Para se refletir sobre objetos ausentes dos sentidos, bastam a imaginação e as espécies sensíveis; para a recordação de conceitos e conhecimentos previamente adquiridos, basta o intelecto, que retém as espécies inteligíveis. A continuidade entre o conhecimento intelectual e as coisas singulares se estabelece pelos sentidos internos. Na aquisição de um saber e na utilização de um saber já adquirido, o entendimento tem como objeto próprio as formas universais e imateriais, no entanto, por estar unido ao corpo, recorre à imaginação e às restantes potências sensíveis ou sentidos internos - embora, por serem materiais e agirem pelos órgãos corpóreos, tenham por objeto próprio o particular (Sobre a verdade X, 2; 3 ad 1; Tomás de Aquino, 1947, I, 79, p.6-7).

Em sua investigação sobre a abstração nos modos de intelecção em Tomás de Aquino, D'Arc Ferreira expõe os cinco níveis de operação para a perfeição da potência sensível, os quais permitirão o conhecimento sensível (Ferreira, 2001, p.124-8); dentre os quatro últimos, incluem-se os sentidos internos (Tomás de Aquino, 1947, I, 78, p.4). Há os sentidos próprios ou particulares, que captam um existente a partir de suas qualidades extrínsecas cor; som; gosto; odor; quente; frio; duro; mole -, cada uma corresponde imediata e exclusivamente a um determinado sentido externo - respectivamente: visão; audição; paladar; olfato e tato -, colocando o animal diante do mundo a sua volta. ${ }^{6}$ Depois, o sentido comum (sensus communis) centraliza os dados dos sentidos externos, comparando-os e unificando-os, o que gera as percepções. O terceiro nível é representado pela fantasia ou imaginação (phantasia, imaginatio) que conserva e arquiva as percepções ou imagens das coisas, funciona como uma memória sensível, de tipo passiva. O quarto nível permite ao animal discernir aspectos dos corpos sensíveis que os sentidos externos não percebem, a saber: o útil, o nocivo, etc. Chama-se estimativo (aestimativa) uma espécie de instinto inato que leva, por exemplo, a ovelha a fugir do lobo. Quanto a isto, no homem, o estimativo é substituído

5 Pela diferença com Tomás acerca da memória, Nicolas de Jésus-Marie, no séc. XVII, evitou falar desta nas obras joãocrucianas (ver Bord, 1971, p.300-303).

6 O sentido interno precede ao externo ao julgar os atos deste, avisando ao animal o que lhe falta ou lhe é deficiente, por exemplo: o olho está fechado e por isso não vê; neste ponto, o sentido externo também julga seus sensíveis próprios, assim, o ouvido julga sobre o que lhe falta ou lhe é suficiente num som, sentindo-o suave ou estridente (ver Castello Dubra, 2001, p.40). 
pela cogitativa (vis cogitativa) ou razão particular, assim denominada por adquirir novas funções em conexão com as operações racionais do entendimento - conceber, julgar, raciocinar e elaborar -, fazendo uma ponte entre o pensamento abstrato e as experiências singulares. Por fim, o animal reaviva imagens antigas, restituindo-as, o que lhe permite utilizar-se delas; tal percepção requer capacidade rememorativa (virtus rememorativa), uma memória intelectual e ativa (reminiscentia) capaz de despertar lembranças passadas para reapresentá-las à consciência atual, o que demanda esforço.

No concernente ao número ou à função dos sentidos internos não havia consenso entre os escolásticos. O carmelita João Baconthorp - autor relevante após o Capítulo Geral de 1510 que exigia seus escritos nas bibliotecas conventuais (Crisógono, 1982, p.60-3) - acompanha Al-Ghazali (Bord, 1971, p.82, n.11), que entendia haver seis sentidos internos: o sentido comum, o estimativo, o cogitativo, a memória, a imaginação e a fantasia; para Avicena (Ibn Sina), cinco: o sentido comum da fantasia, o estimativo, o cogitativo, a memória e a imaginação; Tomás e Averróis (Ibn Rushd) enumeram quatro: a imaginação ou fantasia, o sentido estimativo (ou cogitativo), a memória e o sentido comum (Tomás de Aquino, 1947, I, 78, p.4).

João da Cruz assume o sentido comum da fantasia $(\mathrm{ChB} 3,69)$ da antropologia aviceniana, ${ }^{7}$ receptáculo das formas dos objetos percebidos pelos sentidos externos. Isso reduziu ainda mais o número de sentidos internos, com a junção da imaginação e da fantasia perfazendo um só sentido - apesar de o texto que as identifica ainda mantenha uma função distinta para cada uma delas:

os sentidos de que aqui particularmente falamos são os sentidos corporais [interiores], ${ }^{8}$ que se chamam imaginação e fantasia, os quais ordenadamente se servem um ao outro; porque um discorre imaginando, e o outro forma a imaginação ou o imaginado fantasiando; e para nosso propósito o mesmo é tratar de um ou de outro. Pelo que, quando não os nomearmos os dois, tenha-se por entendido segundo aqui dissemos deles. $(2 \mathrm{~S} 12,3 \text {, grifo nosso })^{9}$

O sentido comum corporal é um sentido interno com dupla função, por englobar a fantasia e o papel discursivo da imaginação (Bord, 1971, p.82) num único sentido comum; este, uma central de recepção e arquivo das

7 No que se refere às diversas classificações dos sentidos internos propostas por Avicena (ver Attie Filho, 2000, p.129-35).

8 Os termos entre colchetes foram acrescentados pelo editor para melhor compreensão da frase (digno de nota é João da Cruz nunca empregar interno ou externo, incluindo as respectivas variantes, e sim interior ou exterior).

9 Em CB 18, 7, João da Cruz inclui a memória como um dos sentidos internos; evidentemente por lapso. Basta observar a estrutura global dos livros 2 e 3 da Subida e o texto de ChB 3, 18-22 (Payne, 1990, p.21). 
imagens - as formas e figuras (2S 3, 2; 12, 3; 3S 13, 4; 2N 25, 3; etc.) - produzidas pelos sentidos externos. ${ }^{10}$ As impressões das coisas sensíveis são recolhidas pela fantasia. Esta armazena as impressões como imagens particulares que as representam, as espécies sensíveis $(2 \mathrm{~S} 16,2)$ ou fantasmas (2S 1, 2; 3, 2; CB 14, 14; 18, 7; 40, 5; ChB 2, 34; CA 13, 14). Das imagens, o entendimento ativo engendra espécies inteligíveis que, recebidas no entendimento passivo, permitem-lhe formular o conceito que gera o conhecimento. As espécies sensíveis não informam diretamente a memória, uma potência espiritual para nosso autor, mas são guardadas na fantasia identificada com o sentido comum, o sentido comum do corpo.

Imagens novas, ainda mais complexas - a exemplo de coisas inexistentes, montanhas de ouro ou palácios de pérolas $(2 S$ 12, 4) - são construídas na mente pela imaginação; esta recombina os dados fornecidos pelos sentidos ao receber os conteúdos da fantasia $(2 S \mathrm{~S}, 5 ; 12,3-5 ; 3 S \mathrm{~S} 4$, 1). Além disso, por sua natural inclinação a divagar (1N 8, 3; 9, 8), é responsável pelo fluxo discursivo de impressões da mente.

O funcionamento da imaginação e da fantasia depende de sua cooperação com a memória. Por meio dela, a imaginação constrói as novas imagens; com seu auxílio, coloca-as na fantasia a fim de preservá-las. Cabe notar que a recíproca assistência entre a parte sensível e as potências espirituais indica a unidade da pessoa para João da Cruz (2S 8, 5; 16, 2; Bord, 1971, p.84-5). No entanto, a forma discursiva da meditação $(2 \mathrm{~S} 12,3)$ e suas imagens mentais, indispensáveis no início da vida espiritual por conduzirem os apetites para coisas elevadas (1N 8, 3), oferecem um remoto conhecimento da essência divina por se apoiarem em representações de coisas sensíveis. ${ }^{11}$

Cabe ressaltar que ao assumir a divisão da alma em três potências espirituais (ver por exemplo 2N 8, 2), João da Cruz também não se identifica com Agostinho a respeito do papel exercido pela memória: um receptáculo que exclusivamente armazena idéias e conhecimento (Conf. X, 8, 12; XI, 18, 23; 20, 26). ${ }^{12}$ Para João da Cruz, a memória possui outras e variadas funções: recordar, representar, atualizar e reviver $(3 \mathrm{~S} 3,5 ; 7,2 ; 9,4 ; 13,1 ; 14,1$; ChB 3, 21); seja voluntária, pela reminiscência (3S 2, 7; 14, 1; Bord, 1971,

10 Bord observa que João da Cruz retomaria a simplicidade do esquema aristotélico presente ao longo da terceira parte do tratado Sobre a alma (427 a 15-429 a 10) (Bord, 1971, p.82, n. 11).

11 Coerentemente, João da Cruz chama de sentido uma atividade radicalmente espiritual como a meditação porque exercida pelas potências espirituais numa abertura às coisas do mundo mediante os sentidos, diferenciando-se radicalmente da atitude contemplativa (ver Urbina, 1956, p.169; Garrigou-Lagrange, 1951, p.419).

12 Para uma análise da mens enquanto receptáculo da vida divina em Agostinho e Tomás (ver Gardeil, 1927, v.I, p.1s.). 
p.76-7), ou espontaneamente. ${ }^{13} \mathrm{Um}$ sinal de que a memória não é mero receptáculo é que o esvaziamento de suas apreensões não oferece dano mas aperfeiçoa os hábitos adquiridos das ciências (CB 26, 16) por sua articulação com a fantasia e a alma em si (3S 7, 1; 13, 6-8; 14, 1-2; Bord, 1971, p.8196), que, por sua vez, conservam conhecimentos e idéias mesmo quando a alma está absorvida em Deus.

A memória recebe e guarda as espécies sensíveis produzidas pela percepção natural (ou pela intervenção sobrenatural); pelas espécies sensíveis, a imaginação constrói notícias e imagens, depositando-as na fantasia com o auxílio da memória, que as preserva $(2 \mathrm{~S} 8,5)$. Acrescente-se ainda a assistência dada pela memória ao entendimento em sua seleção das espécies sensíveis para que, a partir delas, possa fazer sua consideração e julgamento $(2 \mathrm{~S} 16,2)$.

A dificuldade na distinção da memória com relação ao entendimento deve-se às suas formas, figuras e notícias. As apreensões da memória se dividem no terceiro livro da Subida por meio das mesmas categorias já empregadas para tratar da purificação do entendimento no livro anterior, ${ }^{14}$ reportando-se repetidamente a elas (3S 1, 1-2; 2, 15; 13, 3; 14, 2).

Na percepção de uma coisa sensível e na lembrança desta percepção leva-se em conta o mesmo conceito, a despeito de, na última, não se usar os sentidos externos. A memória e o entendimento, porém, por ficarem sujeitos às mesmas limitações naturais, pertubando-se com intensos desejos, carecem igualmente de purificação.

Esta rédea e freio (das paixões e apetites desordenados), não a pode ter de verdade a alma não se esquecendo e apartando as coisas de si, de onde lhe nascem as afeições; e nunca lhe nascem na alma perturbações senão a partir das apreensões da memória, porque, esquecidas todas as coisas, não há coisa que perturbe a paz nem que mova os apetites, pois, como dizem, o que o olho não vê o coração não deseja. (3S 5, 1)

Logo, visto que a memória pode trazer o mal, deve ela ser purificada. Ela busca no arquivo de imagens e vivências - na fantasia ou no sentido comum da alma - dados que alimentem a agressividade, a cobiça, a paixão,

13 Pelo inconsciente (1N 4, 4), pela vontade (3S 13, 1), pelo demônio (3S 4, 2) ou por Deus (CB 35, 5 e ChB 1, 17).

14 No segundo livro da Subida, as apreensões do entendimento provêm por via natural ou sobrenatural (cap.10). Por via natural, provém da ação dos sentidos corporais (tratado no primeiro livro) ou da meditação discursiva (caps. 12-15). Por via sobrenatural, são corporais (externos, cap.11, ou internos, caps. 16-22) ou puramente espirituais. As puramente espirituais, de maior relevo para nossa análise, podem ser particulares e distintas (cap.23), ou, confusas, obscuras e gerais, isto é, a contemplação, fim do caminho espiritual. Apenas as particulares e distintas subdividem-se em visões (cap.24), revelações (caps. 25-28), palavras interiores (caps. 29-31) e sentimentos espirituais (cap.32). 
soberba e vingança; com o agravante de que não tem limites de duração, o que lhe permite realizar continuamente sua ação degradante. ${ }^{15} \mathrm{E}$ disto a cada momento tiramos experiência, pois vemos que, cada vez que a alma se põe a pensar alguma coisa, fica mobilizada e alterada, no pouco ou no muito, sobre aquela coisa, segundo seja a apreensão: se pesada e molesta, tira tristeza [ou ódio, etcétera]; se agradável, tira apetite e gozo, etc. (3S 5, 2). A alma, quando retém (3S 12, 1; 14, 2) e apreende (3S 2, 14; 5, 3; 7, 2; 8, 1) preferencialmente a lembrança de amarguras passadas, acaba não se abrindo para a ação divina que ora se lhe manifesta. Para que participe diretamente da comunhão divina, tanto quanto as demais potências espirituais, a memória deve esvaziar-se

de todas as formas que não são Deus, ${ }^{16}$ pois Deus não está sob forma nem sob nenhuma notícia distinta, como o dissemos na Noite do entendimento; e, pois, ninguém pode servir a dois senhores (Mt 6, 24), como diz Cristo, não pode a memória estar juntamente unida com Deus e com as formas e notícias distintas, e como Deus não tem forma nem imagem que possa ser compreendida pela memória, daqui é que, quando está unida com Deus, como também por experiência se vê cada dia, fica sem forma e sem figura $(3 \mathrm{~S} 2,4)$

Os toques interiores e puramente espirituais da divina união não implicam numa imagem ou forma corporal particular, apreensões relembradas intelectual e espiritualmente pela forma que na alma deixa impressa, que também é forma ou notícia ou imagem espiritual ou formal pela qual se relembra $(3 \mathrm{~S} 14,1)$. Tais representações e apreensões, imaginativas e sobrenaturais, deixam uma forma impressa na alma $(3 S \mathrm{~S} 7,1)$; a rigor, imprime-se não a forma imaginativa mas seu efeito espiritual (Bord, 1971, p.88). Aqui, João da Cruz remete às conhecidas visões imaginárias e espirituais (2N 2, 3), também denominadas de puramente espirituais, mas que devem ser rejeitadas por fornecerem um conhecimento claro e distinto, não ao geral e obscuro que deixa a alma livre para o encontro com Deus (3S 6; Bouillard, 1962, p.491ss e p.500):

às quais chamo puramente espirituais, porque não são comunicadas ao entendimento pelos sentidos corporais, como acontece nas (apreensões) corporais imaginárias; mas, sem meio algum do sentido corporal, exterior ou interior, se oferecem ao entendimento clara e distintamente por via sobrenatural, de modo passivo, isto é, sem que a alma coopere com algum ato ou obra de sua parte, ao menos ativamente $(2 \mathrm{~S} 23,1)$.

15 Por isso a mortificação da memória não prejudica a conservação de experiências e conhecimentos, que são independentes de sua possível má utilização pela memória.

16 O manuscrito Alcadete acrescenta o de, ficando de Deus; no entanto, o que vem de Deus evidentemente impede a direta e imediata união com Ele. 
João da Cruz distingue as graças místicas acidentais e corporais - as notícias distintas e particulares são visões, locuções e revelações consoante o segundo livro da Subida $(2 N$ 17, 5) - e a graça mística essencial e espiritual - a notícia geral e obscura da união de amor - comunicação sintética e totalizante por abarcar a alma inteira em seu relacionamento com Deus (Ruiz Salvador, 1995, p.247-8).

Os sentidos corporais fornecem valiosas analogias às experiências espirituais. Por isso os sentidos da visão, audição e tato assumem maior relevância pelas visões, locuções e toques substanciais que tais experiências motivam. A visão e a audição dirigem-se a uma experiência de caráter intelectual; outros, em especial o tato, teriam primazia ante uma experiência de tipo místico, fortemente afetiva, pelo contato interior na substância da alma (Ruiz Salvador, 1995, p.254-7).

Sendo corporal, a fantasia não tem capacidade para receber as formas puramente espirituais; semelhante à imagem num espelho (2S 16, 2), a própria alma serve de receptáculo para tais formas (3S 13, 7). Aí reside o sentido comum da alma (ou substância da alma) mencionado em ChB 3, 69, capaz de experienciar, reter e saborear os objetos das potências espirituais (Bord, 1971, p.90-1).

Tem-se, então, simetricamente, os dois receptáculos dos quais a memória extrai as formas espirituais: na parte sensível, o sentido comum corporal ou a fantasia; na espiritual, o sentido comum da alma. Sob este ângulo, a purificação e o esvaziamento da memória não prescreverem o esquecimento do que se conhece ou se lembra. Apenas manifestam a necessidade de a memória ficar livre de considerações particulares - pois o pensamento das criaturas impede a união de amor - numa esperança que a purifica a fim de deixá-la livre para receber a comunicação divina (3S 2, 1; Urbina, 1956, p.220):

que também a memória embaraçada impede o bem espiritual, claramente se prova pelo dito, porque a alma alterada, que não tem fundamento de bem moral, não é capaz, enquanto tal, do espiritual, o qual não se imprime senão na alma moderada e posta em paz. E, além disto, se a alma faz presa e caso das apreensões da memória, como quer que a alma não pode advertir mais que uma coisa, se se emprega em coisas apreensíveis, como são as notícias da memória, não é possível que esteja livre para o incompreensível, que é Deus; porque; [como sempre dissemos], para que a alma vá a Deus, antes que compreendendo há de ir não compreendendo; há de trocar o comunicável e compreensível pelo incomunicável e incompreensível (3S 5, 3).

Por recordar e antecipar a vida na consciência, a memória sintetiza a cada momento o que é e tem, o que fez ou espera (Ruiz Salvador, 1995, p.211). Mais do que imagens, formas, etc., a memória faz possuirmos a nós mesmos (Urbina, 1956, p.221); noutros termos, isto significa que a contemplação mística deve alcançar a memória radical, a posse da substância da alma (idem, p.222). 
BARREIRA, Marcelo Martins. The memory on mistagogy of John of the Cross. Trans/ Form/Ação, (São Paulo), v.30(1), 2007, p.41-50.

- ABSTRACT: The importance of the memory in the Ascent of Mount Carmel come of its capacity to keep the pleasant or disagreeable experiences, allowing them that they are gone deep and if ramifies in the soul, with serious repercussions in the spiritual life. The memory searchs, in the archive of images and experiences, data that feeds the aggressiveness, covet it, the passion, magnificent and revenge; with the aggravating one of that it does not have duration limits, what it allows it to carry through this continuously its action. The soul, when it retain and it apprehends in preferential way the souvenir of passed a bitterness, finishes if not opening for the divine action that however manifest in it.Therefore, so that it participates directly of the divine communion, as the others spirituals powers, the memory must be emptied. The purification and the empty of the memory not to prescribe the forgetfulness of what it is known or remember, it only shows the necessity of it to be free of particular deliberation in a hope that the purify in order to leave it free to receive the divine communication.

- KEYWORDS: soul; memory; union of love; John of the Cross; God.

\section{Referências bibliográficas}

AGOSTINHO, S. Confissões. Petrópolis: Vozes, 1999.

A Trindade. São Paulo: Paulus, 1995.

ARISTÓTELES. Acerca del alma. Madrid: Gredos, 1994.

ASTiGARRAGA, J. L.; BORRELL, A. \& MARTín DE LUCAS, F. J. Concordancias de los escritos de San Juan de la Cruz. (edição eletrônica). Roma: Teresianum, 1990.

ATTIE FILHO, M. Os sentidos internos em Ibn Sina. Porto Alegre: Edipucrs. 2000.

BARUZI, J. Saint Jean de la Croix et le problème de l'expérience mystique. Paris: Alcan, 1931.

BORD, A. Mémoire et espérance chez Jean de la Croix. Paris: Beauchesne, 1971.

BOUILLARD, H. "La 'sagesse mystique' selon Saint Jean de la Croix." In: Recherches de Science Religieuse, v.50. Paris: Joingt Jouve, 1962.

CASTELLO DUBRA, J. A. "La Prueba Agustiniana de la Existencia de Dios". In: Ágora Filosófica, v.2. Recife: Unicap, 2001.

FERREIRA, A. D'Arc. "A abstração em Santo Tomás de Aquino: uma investigação sobre a importância da abstração nos modos de intelecção". In: Ágora Filosófica, v.2. Recife: Unicap, 2001.

GARCIA, C. Juan de la Cruz y el misterio del hombre. Burgos: Monte Carmelo. 1990.

GARDEIL, A. La Structure de l'Âme et l'Expérience Mystique. v.2. Paris: Victor Lecoffre, 1927. 
GARRIGOU-LAGRANGE, R. Traité de théologie ascétique et mystique. Les trois ages de la vie intérieure. Prélude de celle du ciel. Paris/Montreal: Cerf/Lévrier, 1951.

JOSAPHAT, C. Contemplação e Libertação - Tomás de Aquino, João da Cruz, Bartolomeu de Las Casas. São Paulo: Ática, 1995.

JUAN DE LA CRUZ, S. Obras Completas. Editada por Lucinio Ruano. Madrid: BAC, 1982.

MANCHO DUQUE, M. J. El símbolo de la noche en San Juan de la Cruz. Salamanca: Ed. Universidad, 1982.

Palabras y Símbolos en San Juan de la Cruz. Madrid: Fund. Univ.Esp./ Univ.Pont.de Salamanca, 1993.

MARITAIN, J. Distinguer pour unir ou Les degrés du savoir. Paris: Desclée de Brouwer, 1946

MOREL, G. Le sens de l'existence selon saint Jean de la Croix. v.3. Paris: Aubier, 1960.

MUÑOZ DELGADO, V. "Filosofía, teología y humanidades en la Universidad de Salamanca durante los estudios de San Juan de la Cruz (1564-1568)". In: VV.AA. Juan de la Cruz, espiritú de llama. Estudios como ocasión del cuarto centenario de su muerte (1591-1991). Kampen/Roma: Kok Pharos Publishing House/ Institutum Carmelitanum, 1991.

ORCIBAL, J. San Juan de la Cruz y los Místicos Renano-Flamencos. Madrid: Fund. Univ.Esp./Univ.Pont.de Salamanca, 1987.

PAYNE, S. John of the Cross and the Cognitive Value of Mysticism - An Analysis of Sanjuanist Teaching and its Philosophical Implications for Contemporary Discussions of Mystical Experience. Dordrecht/Boston/London: Kluwer Academic Publishers, 1990.

RUIZ SALVADOR, F. Introducción a san Juan de la Cruz. El escritor, los escritos, el sistema. Madrid: La Editorial Católica, 1968.

Místico e Mestre São João da Cruz. Petrópolis: Vozes, 1995.

SACRAMENTADO, C. J. de. Vida de San Juan de la Cruz. Madrid: BAC, 1982.

TOMÁS DE AQUINO, S. Le Questioni disputatae. La veritá. Bologna: Studio Dominicano, 1992.

Suma de teologia. v.16. Madrid: BAC, 1947ss.

URBINA, F. La persona humana en san Juan de la Cruz. Madrid: Instituto Social León XIII, 1956.

VAN STEENBERGHEN, F. O tomismo. Lisboa: Gradita, 1990.

VAZ, H. C. de L. Experiência mística e filosofia na tradição ocidental. São Paulo: Loyola, 2000.

VV.AA. Dictionnaire de Spiritualité Ascétique et Mystique - Ascétique et Mystique, Doctrine et Histoire. Paris: Beauchesne, 1932ss. 